\title{
A Rare Case of Papillary Fibroelastoma Involving The Tricuspid Valve. A single Center experience over a period of 22 years (1999-2021)
}

\author{
Claudia Calia ${ }^{1}$, Vittoria Lodo ${ }^{1}$, Guglielmo Actis Dato ${ }^{1}$, Gianfranco Cappuccio ${ }^{1}$, Enrico \\ Italiano $^{1}$, Mariangela Addonizio ${ }^{1}$, Andreea Stefan ${ }^{1}$, and Paolo Centofanti ${ }^{1}$ \\ ${ }^{1}$ Azienda Ospedaliera Ordine Mauriziano di Torino
}

May 10, 2021

\begin{abstract}
Background and aim Papillary fibroelastoma (PFE) represents only $16 \%$ of the benign cardiac tumor and approximately $15 \%$ of these are located on tricuspid valve. Materials and Methods Over a period of 22 years (1999-2021) we observed 75 pts with cardiac tumors at our Center over 9650 pts operated on. Most of them were mixoma but in 10 cases histology showed a PFE. We describe a rare case (1/75 of cardiac tumors) of a tricuspid valve PFE in a 69-year-old patient. Trans-thoracic echocardiography demonstrated a mobile mass $(20 \mathrm{x} 10 \mathrm{~mm})$, adhering to the atrial side of the septal leaflet of the tricuspid valve. In consideration of the mobility of the mass and the consequent high embolic risk, surgical removal was made. Patient underwent surgery through a median sternotomy on CPBP. A "gelatinous" mass adhering to the tricuspid leaflet was found and completely removed. The postoperative course was uneventful. The pathological evaluation confirmed the diagnosis of PFE. Conclusions PFE of the tricuspid valve is rare entities being in most cases found incidentally. In our experience the incidence of this tumor in this location is $1 / 10000$ cases of cardiac surgery. Although most patients are asymptomatic, surgical treatment is nevertheless recommended in consideration of the high embolic risk.
\end{abstract}

\section{Hosted file}

Main Document.pdf available at https://authorea.com/users/413069/articles/521521-arare-case-of-papillary-fibroelastoma-involving-the-tricuspid-valve-a-single-centerexperience-over-a-period-of-22-years-1999-2021 


\begin{tabular}{|l|c|c|}
\hline & $\mathbf{n}$ & $\%$ \\
\hline Males & 27 & 36 \\
\hline Females & 48 & 64 \\
\hline Mean age (years) & $63,2 \pm 10,3$ & \\
\hline Logistic EuroScore & $5 \pm 2,7$ & \\
\hline & & \\
\hline Myxoma & 55 & 73 \\
\hline Fibroelastoma & 10 & 13 \\
\hline Malignacy & 10 & 13 \\
\hline Mean CPBP time (min) & $73 \pm 53$ & \\
\hline Mean Ao X clamp (min) & $35 \pm 18$ & \\
\hline & & \\
\hline Complications & & \\
\hline Death (0-30 days) & $1 / 75$ & 1,3 \\
\hline Neurologic & $5 / 75$ & 6,5 \\
\hline Cardiac & $3 / 75$ & 3,9 \\
\hline Respiratory & $4 / 75$ & 5,2 \\
\hline Kidney & $2 / 75$ & 2,6 \\
\hline
\end{tabular}




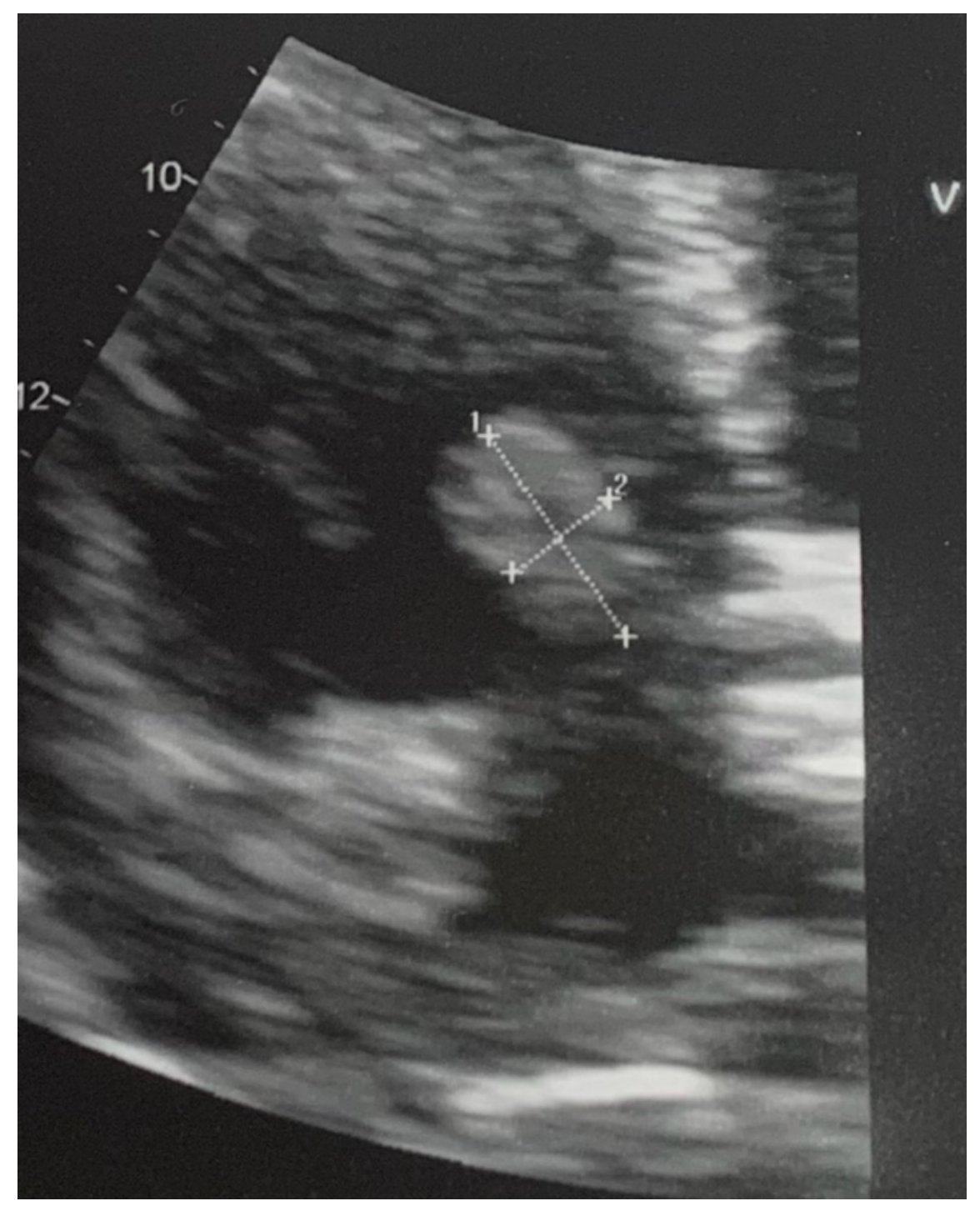



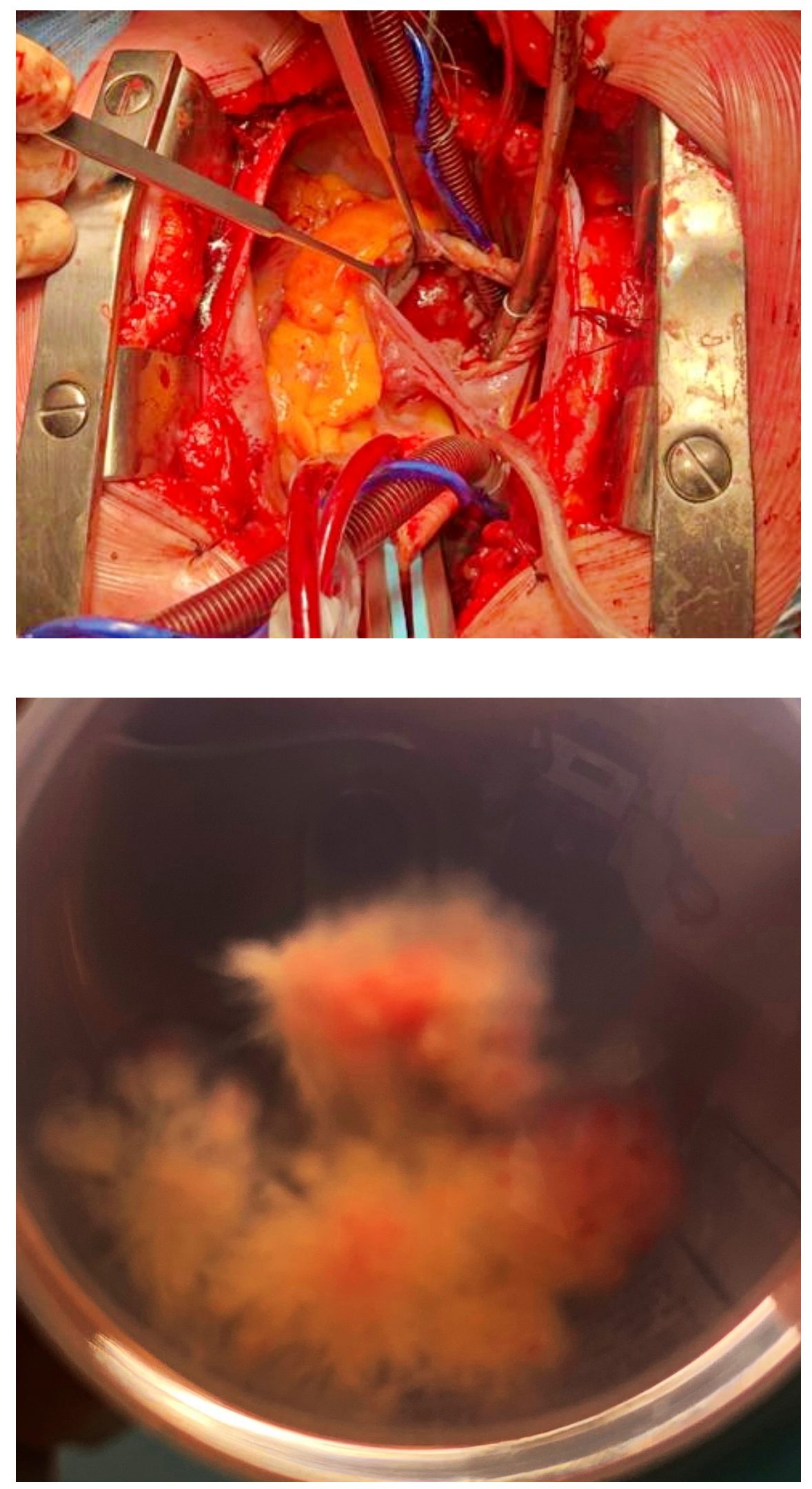